
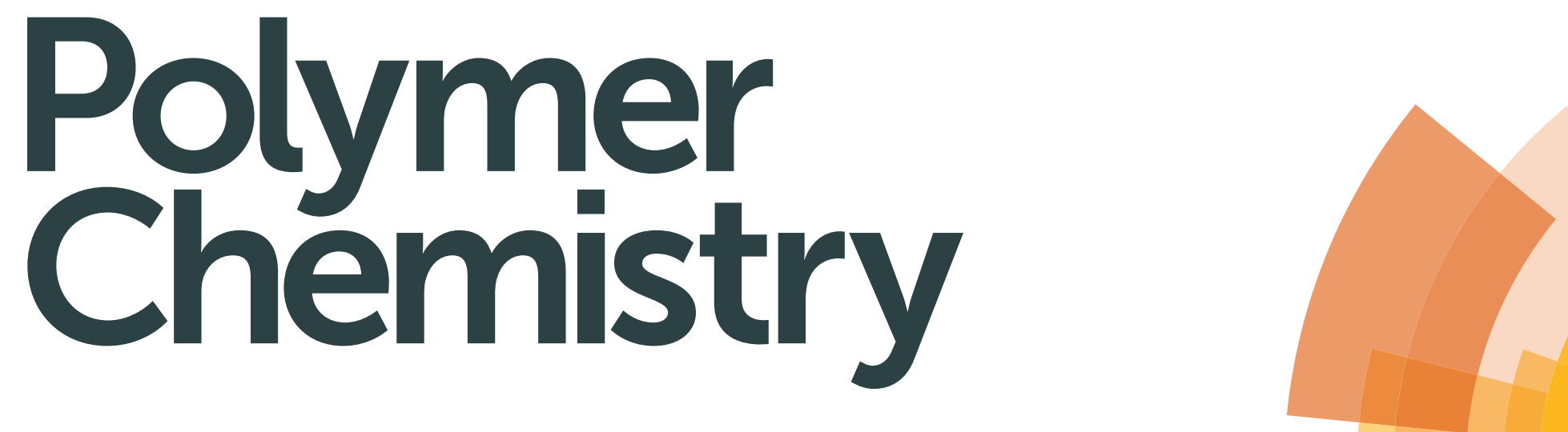

www.rsc.org/polymers

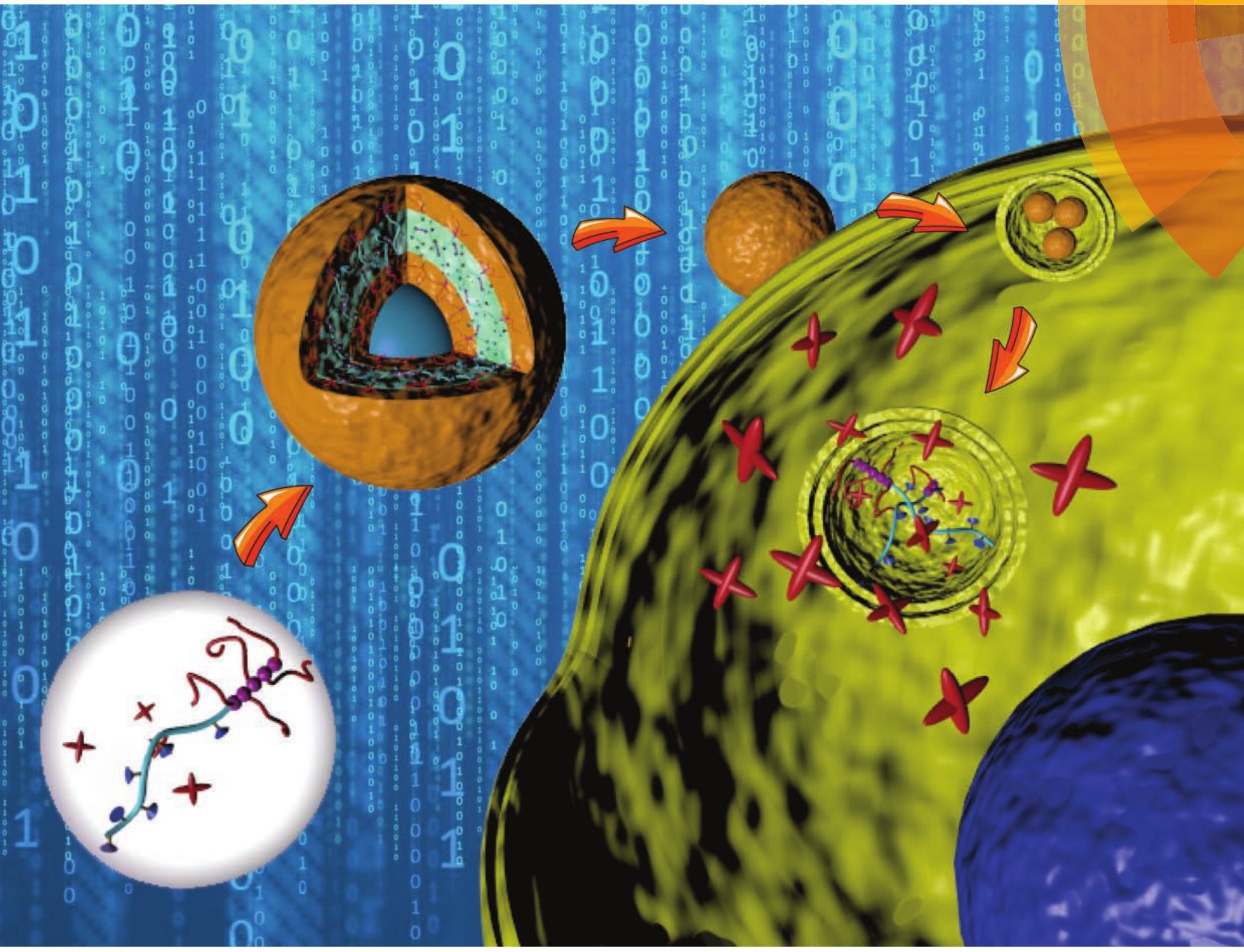

ISSN 1759-9954

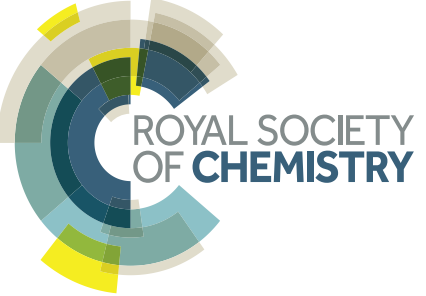




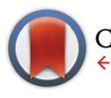

CrossMark \& click for updates

Cite this: Polym. Chem., 2015, 6, 35

\title{
Degradable cross-linked polymer vesicles for the efficient delivery of platinum drugs $\uparrow$
}

\author{
Q. Fu, J. Xu, K. Ladewig, T. M. A. Henderson and G. G. Qiao*
}

Received 15th August 2014,

DOI: $10.1039 / c 4 p y 01123 f$

www.rsc.org/polymers Accepted 15th September 2014

\begin{abstract}
Nontoxic and acid-degradable cross-linked polymeric vesicles as efficient nanocarriers for the delivery of platinum drugs are reported. Well-defined linear-brush diblock copolymers were synthesized via a robust ring opening metathesis polymerization technique and self-assembled in a selective solvent to form polymeric vesicles with bilayer structure. Vesicles were subsequently cross-linked using acid-degradable diamino ketal cross-linkers and the anticancer drug cis-platin was conjugated to the vesicles with a high loading content (17.6\%) through the formation of stable chelate ring structure. This acid-degradable linker leads to a faster drug release in saline under acidic conditions $(\mathrm{pH}=5.5)$ such as those encountered in the late endosome compared to physiological $\mathrm{pH}(\mathrm{pH}=7.4)$. Cancer cells tended to readily internalize the vesicles and dose-response cytotoxicity studies suggested that the drug-loaded cross-linked vesicles were more efficient in delivering the platinum drug into cancer cells compared to internalization of the free drug. Additionally, polymer vesicles prior to platinum conjugation were nontoxic towards cancer cells.
\end{abstract}

\section{Introduction}

cis-Dichlorodiaminoplatinum(II) (cisplatin, CDDP) is one of the most potent chemotherapy drugs, which has been widely used to treat various types of cancers, including sarcomas, lung, ovarian, testicular, lymphomas, and germ cell tumors. ${ }^{1}$ This platinum complex acts in vivo, by binding to and crosslinking of DNA, which ultimately triggers apoptosis. ${ }^{2,3}$ However, platinum drugs have well recognized drawbacks, such as inactivity when administered orally, low solubility in water, very short half-lives in the body, and induction of severe side-effects including nausea, vomiting, renal dysfunction, neurotoxicities as well as drug resistance. ${ }^{1,4}$

In recent years, significant effort has been devoted to develop matrix-based systems for the delivery of platinum drugs $^{5-9}$ since these have the capability to increase drug solubility, protect drugs from undesirable biological binding events, reduce systemic toxicity and localize platinum drugs at tumor sites via the enhanced permeability and retention (EPR) effect. $^{10,11}$ Stenzel and co-workers ${ }^{12,13}$ reported the synthesis of polymer micelles for cisplatin delivery and controlled

Polymer Science Group, Department of Chemical and Biomolecular Engineering, The University of Melbourne, Parkville, VIC 3010, Australia.

E-mail: gregghq@unimelb.edu.au; Fax: +61-3-83444153

$\dagger$ Electronic supplementary information (ESI) available: Details of the DLS and TEM measurements of polymer vesicles, determination of the platinum conjugation efficiency and platinum loading content. See DOI: 10.1039/c4py01123f $\$$ These authors contributed equally. release. More recently, Johnson et al. ${ }^{14}$ have prepared star-like polymeric nanoparticles carrying multiple therapeutic agents, including doxorubicin, camptothecin, and cisplatin. Although the concept of using matrix systems as platinum carrier has been well established in the laboratory, it is still desirable to design novel more efficient drug delivery systems.

The polymer vesicles, consisting of aqueous interiors entrapped by bilayer lipid-like membranes, are a class of nanoscale self-assemblies from synthetic or natural polymers inspired by complex biological systems such as cells and viral capsids. ${ }^{15-17}$ In contrast to matrix system, polymer vesicles exhibit versatile transport properties, as hydrophobic drugs can be enclosed in the membrane of the carrier, whereas hydrophilic drugs are encapsulated in their aqueous cavity. ${ }^{5}$

Vesicles therefore enable the encapsulation of larger amounts of drugs than matrix systems, which means that much smaller amounts of vectors can be administered. ${ }^{18}$

Recently, we reported a simple and robust approach to fabricate polymer vesicles from linear-brush diblock copolymers. ${ }^{19}$ These synthetic vesicles provided desirable bidentate functionalities within their bilayer membrane which enable the binding of cisplatin by forming a stable platinum complex via 7-member rings. ${ }^{12,20}$ We previously showed that this approach afforded a high drug loading content within the vesicles and a controlled drug release profile in physiological media.

Herein, we report the further development of an ameliorated vesicular system containing acid-sensitive cross-linkers, which can stabilize the assembled structure in physiological media and degrade in the endosomal environment of cells for 
a more efficient cisplatin drug delivery. The polymer vesicles were constructed by self-assembly of well-defined linear-brush polyoxanorbornene-based diblock copolymers in dry acetone, followed by cross-linking between pendant anhydrides and acid-cleavable diamino ketal cross-linkers. Hydrolysis of the anhydrides led to the formation of diacid functionalities, which were subsequently employed to conjugate cisplatin. Vesicles with and without drugs were characterized by dynamic light scattering (DLS), transmission electron microscopy (TEM) and thermogravimetric analysis (TGA). Drug release profiles, cytotoxicity and cellular uptake of drug-loaded vesicles were then investigated in detail.

\section{Experimental}

\section{Materials}

$N$-Propargylamine (98\%), copper(I) bromide (CuBr, 98\%), $N, N, N^{\prime}, N^{\prime \prime}, N^{\prime \prime}$-pentamethyldiethylenetriamine (PMDETA, 99\%), $2^{\text {nd }}$ generation Grubbs catalyst $\left(\mathrm{H}_{2} \mathrm{IMes}\right)\left(\mathrm{PCy}_{3}\right)(\mathrm{Cl})_{2} \mathrm{RuCHPh}$, cis-dichlorodiaminoplatinum(II) (CDDP, 99.9\%), 2,2'-(propane2,2-diyl bis(oxy))diethanamine (PDDE), $N$-(3-dimethylaminopropyl)- $N$ '-ethylcarbodiimide hydrochloride (98\%, EDC), anhydrous pentane $(\geq 99 \%)$, anhydrous pyridine $(99.8 \%)$ and phosphate-citrate buffer tablet were all purchased from Aldrich and used as received. Phosphate-buffered saline (PBS, Life technologies), paraformaldehyde (Life technologies) $\mathrm{N}, \mathrm{N}$ dimethylformamide (DMF, 99.8\%, Merck), $n$-hexane (AR, Chem-Supply) and diethyl ether (AR, Chem-Supply) were also used as received. 4',6-Diamidino-2-phenylindole (DAPI) and Alexa Fluor® 594 (AF594) were purchased from Life Technologies and used as received. Acetone (AR, Chem-Supply) was distilled from calcium hydride under argon. Tetrahydrofuran (THF, AR, Chem-Supply) was distilled from benzophenone and sodium metal under argon. exo-7-Oxabicyclo(2.2.1)-5-heptene2,3-dicarboxylic anhydride (oxa-norbornenyl anhydride, ONBAn), ${ }^{21} \omega$-oxanorbornenyl poly(ethylene oxide) (ONB-PEG, $\left.M_{\mathrm{n}}=2.0 \mathrm{kDa}\right)$ macromonomer, ${ }^{22}$ and pyridine modified $2^{\text {nd }}$ generation Grubbs catalyst $\left(\mathrm{H}_{2} \mathrm{IMes}\right)(\mathrm{pyr})_{2}(\mathrm{Cl})_{2} \mathrm{RuCHPh}^{23}$ were synthesized according to literature procedures.

\section{Instruments}

Gel permeation chromatography (GPC) (THF as eluent) was performed on a Shimadzu liquid chromatography system fitted with a Wyatt DAWN EOS multi-angle laser light scattering (MALLS) detector (690 nm, $30 \mathrm{~mW}$ ) and a Wyatt OPTILAB DSP interferometric refractometer $(690 \mathrm{~nm})$, using three Phenomenex Phenogel columns (500, 104, and 106 A porosity; $5 \mu \mathrm{m}$ bead size) operated at $1 \mathrm{~mL} \mathrm{~min}^{-1}$ with column temperature set at $40{ }^{\circ} \mathrm{C}$. Astra software (Wyatt Technology Corp.) was used to process the data to determine the molecular weights based on the assumption of $100 \%$ mass recovery of the polymer where the $d_{\mathrm{n}} / d_{\mathrm{c}}$ value was unknown. ${ }^{1} \mathrm{H}$ NMR spectroscopic analysis was performed on a Varian Unity Plus $400 \mathrm{MHz}$ spectrometer using the deuterated solvent as reference. Hydrodynamic diameters $\left(D_{\mathrm{h}}\right)$ and size distributions of the nano- particles in aqueous solutions were determined by dynamic light scattering (DLS). DLS measurements were performed using a Malvern high performance particle sizer (HPPS) with a $3.0 \mathrm{~mW} \mathrm{He}-\mathrm{Ne}$ laser operated at $633 \mathrm{~nm}$ at an angle of $173^{\circ}$ (back scattering) and a constant temperature of $25 \pm 0.1^{\circ} \mathrm{C}$. A laboratory-built humidity-controlled vitrification system was used to prepare the samples for cryo-transmission electron microscopy (cryo-TEM). Humidity was kept close to $80 \%$ for all experiments, and ambient temperature was $22^{\circ} \mathrm{C}$. 200-mesh copper grids coated with perforated carbon film (Lacey carbon film: ProSciTech, Qld, Australia) were used for all experiments. Grids were first glow discharged in nitrogen to render them hydrophilic. $4 \mu \mathrm{L}$ aliquots of the sample were pipetted onto each grid prior to plunging. After 30 seconds adsorption time grids were blotted manually using Whatman 541 filter paper, for approximately 2 seconds. Blotting time was optimised for each sample. Grids were then plunged into liquid ethane cooled by liquid nitrogen. Frozen grids were stored in liquid nitrogen until required. The samples were examined using Tecnai 12 Transmission Electron Microscope (FEI, Eindhoven, The Netherlands) at an operating voltage of $120 \mathrm{kV}$, equipped with a Gatan 626 cryoholder (Gatan, Pleasanton, CA, USA) and an Eagle $4 \mathrm{k} \times 4 \mathrm{k}$ CCD camera (FEI, Eindhoven, The Netherlands). At all times low dose procedures were followed, using an electron dose of 8-10 electrons $\AA^{-2}$ for all imaging. Images were recorded using a magnification in the range $10000 \times$ to $30000 \times$. Thermogravimetric analysis (TGA) was performed on a PerkinElmer Pyris-1 thermogravimetric analyzer, and the samples were heated from 70 to $700{ }^{\circ} \mathrm{C}$ at a heating rate of $10 \mathrm{~K} \mathrm{~min}^{-1}$ under an atmosphere flow $\left(20 \mathrm{~mL} \mathrm{~min}^{-1}\right)$. UV-vis spectrometry was performed on a Varian Cary 50 Bio UV-Visible spectrophotometer using quartz cuvettes with a $1 \mathrm{~cm}$ path length. Confocal microscope was performed on a Leica TCS SP2 confocal microscope.

\section{Synthesis of cross-linked polymer vesicles}

The experimental details of the synthesis of diblock copolymer, poly(ONBAn- $b$-ONB-PEG) via the ring-opening metathesis polymerization (ROMP) can be found in our previous publication. ${ }^{19}$ For the poly $\left(\mathrm{ONBAn}_{35}-b\right.$-ONB-PEG $\left.{ }_{5}\right), M_{\mathrm{n}}(\mathrm{GPC})=$ $14.9 \mathrm{kDa}, M_{\mathrm{w}} / M_{\mathrm{n}}=1.21 .{ }^{1} \mathrm{H}$ NMR $\left(400 \mathrm{MHz}, \mathrm{CDCl}_{3}, 25{ }^{\circ} \mathrm{C}, \delta_{\mathrm{H}}\right.$ ppm): $7.80-7.75(\mathrm{~s}, 1 \mathrm{H},-\mathrm{CH}=\mathrm{C}$ of triazole ring), $6.05(\mathrm{~s}, 2 \mathrm{H}$, $-\mathrm{CH}=\mathrm{C} \boldsymbol{H}_{-}^{-}$, trans $), 5.75\left(\mathrm{~s}, 2 \mathrm{H},-\mathrm{CH}=\mathrm{C} \boldsymbol{H}_{-}^{-}\right.$, cis $), 5.05-4.80(\mathrm{~m}$, $2 \mathrm{H},-\mathrm{CH}-\mathrm{O}-\mathrm{CH}-$, cis) , 4.60 (s, 2H, -N-CH $\left.{ }_{2}^{-}\right), 4.55-4.40(\mathrm{~m}, 4 \mathrm{H}$, $-\mathrm{CH}-\mathrm{O}-\mathrm{CH}-$ trans and $\left.-\mathrm{N}-\mathrm{CH}_{2} \mathrm{CH}_{2} \mathrm{O}-\right), 3.75(\mathrm{~s}, 2 \mathrm{H},-\mathrm{N}-$ $\mathrm{CH}_{2} \mathrm{CH}_{2} \mathrm{O}^{-}$), 3.60-3.40 (m, 4H, - $\mathrm{CH}_{2} \mathrm{CH}_{2} \mathrm{O}-$ ), 3.25-3.05 (m, 5H, $-\mathrm{CH}-\mathrm{C}=\mathrm{O}$ and $\left.-\mathrm{O}-\mathrm{CH}_{3}\right)$.

The formed linear-brush diblock copolymer $\left(M_{\mathrm{n}}=14.9 \mathrm{kDa}\right.$, $100 \mathrm{mg}, 6.71 \times 10^{-6} \mathrm{~mol}$ ) was dissolved in $20 \mathrm{~mL}$ distilled THF at a concentration of $5 \mathrm{mg} \mathrm{mL} \mathrm{m}^{-1}$. The sample was then filtered through a PTFE filter (pore size $0.45 \mu \mathrm{m}$ ). Subsequently, $10 \mathrm{~mL}$ distilled acetone was added dropwise into the solution under moderate stirring at room temperature. The mixture was then dialyzed against distilled acetone for $24 \mathrm{~h}$ using a dialysis membrane (MWCO $7.0 \mathrm{kDa}$ ) to remove THF. The particle size was confirmed by DLS as $\sim 95 \mathrm{~nm}$. 
The nanoparticles with different degrees of cross-linking (DOC, $14 \mathrm{~mol} \%, 28 \mathrm{~mol} \%$ and $56 \mathrm{~mol} \%$ ) were prepared in parallel according to similar procedures. A typical procedure (DOC $=28 \mathrm{~mol} \%)$ can be described as followed. A solution of the cross-linker PDDE $\left(2.7 \mathrm{mg}, 1.67 \times 10^{-5} \mathrm{~mol}\right)$ was prepared in $100 \mu \mathrm{L}$ distilled acetone and added slowly to $5 \mathrm{~mL}$ vesicle solution $\left(10 \mathrm{mg} \mathrm{mL}^{-1}\right)$ with stirring. The mixture was kept stirring overnight. The final solution was dialyzed against distilled acetone for 2 days to remove all impurities using a dialysis membrane (MWCO 7.0 kDa). Morphological observation of the cross-linked vesicle, XV was performed by DLS and TEM.

$50 \mathrm{mg}$ XV were then added into $5 \mathrm{~mL} 0.1 \mathrm{M} \mathrm{NaOH}$ solution. This solution was stirred for $30 \mathrm{~min}$ and then dialyzed against distilled water for 2 days to remove $\mathrm{NaOH}$ using Spectra/Por (Spectrum Laboratories Inc.) regenerated cellulose dialysis membrane (MWCO $5.0 \mathrm{kDa}$ ). After freeze-drying, hydrolysed cross-linked vesicle HXV was obtained as a grey-coloured powder. Morphological observation of the hydrolysed crosslinked vesicles was performed by DLS and cryo-TEM.

\section{Drug loading and release}

The conjugation of cis-platin (CDDP) to the polymer vesicles was achieved by following a slightly modified procedure compared to our previous report. ${ }^{19}$ Thereby incorporation of the CDDP was achieved via the reaction of hydrolysed, cross-linked vesicles (HXV) with a cis-diaminediaqua-platinum(II) complex obtained by hydrolysis of CDDP. Briefly, CDDP (10 mg) was suspended in $10 \mathrm{~mL}$ distilled water and mixed with silver nitrate $\left(\left[\mathrm{AgNO}_{3}\right] /[\mathrm{CDDP}]=1.955\right)$ to form the aqueous complex. The solution was stirred in the dark at room temperature for $4 \mathrm{~h}$. As the reaction proceeded a white precipitate of $\mathrm{AgCl}$ was observed. The mixture was then centrifuged at $4400 \mathrm{rpm}$ for 1 hour to remove the $\mathrm{AgCl}$ precipitate and the supernatant was purified by passing through a $0.22 \mu \mathrm{m}$ filter. HXV (40 mg, dissolved in $4 \mathrm{~mL}$ of DI water) were added to the above CDDP aqueous solution and left to react in a water bath at $37^{\circ} \mathrm{C}$ for $12 \mathrm{~h}$ with gentle shaking resulting in platinum-loaded polymer nanocarriers. The prepared conjugates were purified by dialysis against distilled water using regenerated cellulose dialysis membrane (MWCO $5.0 \mathrm{kDa}$ ), followed by freeze-drying, yielding a light brown powder. The platinum conjugation efficiency to the cross-linked vesicles was determined by TGA as $85.2 \%$ by eqn (1).

$$
f=\frac{m_{\mathrm{Pt}, \text { exp }}}{m_{\mathrm{Pt}, \text { theo }}} \times 100 \%=\frac{W_{\mathrm{Pt}} / M_{\mathrm{Pt}}}{W_{\text {diacid }} / M_{\text {diacid }}} \times 100 \%
$$

where $m_{\mathrm{Pt} \text {, exp }}$ and $m_{\mathrm{Pt} \text {, theo }}$ are the molar amount of Pt determined by experimental data and the theoretical molar amount with $100 \%$ conversion, respectively (assuming that one Pt molecule forms a complex with one diacid repeating unit); $W_{\mathrm{Pt}}$ is the weight percent of Pt measured by TGA; $M_{\mathrm{Pt}}$ is the molecular weight of Pt; $W_{\text {diacid }}$ is the weight percent of diacid repeat units calculated by subtracting the weight percent of crosslinked units; $M_{\text {diacid }}$ is the molecular weight of the diacid repeating unit.
The platinum loading content within the polymer nanoparticles is determined as $17.6 \%$ by eqn (2).

$$
\begin{aligned}
\text { Loading content }= & \frac{\text { amount of loaded CDDP }}{\text { amount of vesicles }+ \text { amount of loaded CDDP }} \\
& \times 100 \%
\end{aligned}
$$

The in vitro release of the CDDP was quantified using a dialysis method. Thereby, the platinum-loaded vesicles (Pt-V, $10 \mathrm{mg}$ ) were dissolved in $4 \mathrm{~mL}$ saline solution $(0.9 \mathrm{wt} \%$ of $\mathrm{NaCl}, 0.15 \mathrm{M})$. The solution was evenly added to two dialysis tubings (MWCO $=3.5 \mathrm{kDa}$ ) and dialyzed against $\mathrm{pH}$ buffer solutions (phosphate-citrate buffers, $\mathrm{pH}=7.4$ and 5.5) $(200 \mathrm{~mL})$ at $37{ }^{\circ} \mathrm{C}$, respectively. $0.9 \mathrm{wt} \%$ of $\mathrm{NaCl}$ was added into these buffer solutions to trigger the platinum drug release. At certain time intervals, the release media was sampled and analysed by means of $o$-phenylenediamine colorimetric assay (o-PDA) according to previously published methods. $^{20,24}$ Samples with an unknown Pt content were added to $1 \mathrm{~mL}$ of $o$-PDA solution in $N, N^{\prime}$-dimethylformamide (DMF) $\left(2 \mathrm{mg} \mathrm{mL} \mathrm{mL}^{-1}\right)$ and heated for $10 \mathrm{~min}$ at $100{ }^{\circ} \mathrm{C}$. The amount of platinum present in the sample was determined by measuring the absorbance at $703 \mathrm{~nm}$ using CDDP as a standard curve. The concentration of platinum released from the conjugate was expressed as a ratio of the amount platinum in the releasing solution and that in the initial sample. The percentage of platinum released was calculated by eqn (3):

$$
\% \text { Release }=\frac{V_{\text {total }}(t) \times C+Y}{Z}
$$

where $V_{\text {total }}(t)$ is remaining volume in the releasing container at time $t, \mathrm{~mL} ; C$ is the concentration of platinum determined from UV-vis measurements, $\mu \mathrm{g} \mathrm{mL} \mathrm{m}^{-1} ; Y$ is the amount of platinum that has already been collected, $\mu \mathrm{g}$; and $Z$ is the total amount of platinum at $t=0$ present in the dialysis bag, $\mu \mathrm{g}$. The experimental data were fitted according to eqn (4):

$$
\% \text { CDDP released }=A \exp (-t / \tau)+y_{0} .
$$

\begin{tabular}{lllll}
\hline & $R^{2}$ & $y_{0}$ & $A$ & $\tau$ \\
\hline pH 5.5 & 0.986 & 83.2 & -72.3 & 47.8 \\
pH 7.4 & 0.981 & 51.2 & -46.5 & 39.1
\end{tabular}

\section{Cell culture}

HeLa cells were maintained in 'complete' DMEM medium (supplemented with $10 \%$ FBS, $1 \times$ GlutaMAX $^{\mathrm{TM}}$, and $1 \times$ antibiotic-antimycotic) in a humidified atmosphere containing $5 \% \mathrm{CO}_{2}$ at $37{ }^{\circ} \mathrm{C}$. Usually, cells were seeded in a T175 flask (ca. $3 \times 10^{6}$ cells $\left.\mathrm{mL}^{-1}\right)$ and passaged twice a week prior to the performance of the subsequent cell viability or cell uptake imaging studies.

\section{Cytotoxicity assay}

Cytotoxicity of the polymers was assessed using Invitrogen's alamarBlue ${ }^{\circledR}$ cell viability reagent following the manufac- 
turer's instructions. Briefly, a 96 well 'mixing plate' with a concentration gradient of the drug-loaded vesicles $\left(2 \times 10^{-6}-4 \times\right.$ $10^{-3} \mathrm{~mol} \mathrm{Pt} \mathrm{L}{ }^{-1}, 1 \times 10^{-7}-2 \times 10^{-4} \mathrm{~mol}$ polymer $\mathrm{L}^{-1}$ ) and corresponding gradients of free polymer, empty vesicles and degraded vesicles $\left(1 \times 10^{-7}-2 \times 10^{-4}\right.$ mol polymer $\left.\mathrm{L}^{-1}\right)$ as well as free drug and degraded drug-loaded vesicle $\left(2 \times 10^{-6}-4 \times\right.$ $10^{-3}$ mol Pt L ${ }^{-1}$ ) was prepared. In another 96 well plate, 'the experimental plate', $80 \mu \mathrm{L}$ of cell suspension was seeded in each well ( $c a$. 10000 cells per well) except for the 'medium blanks' in which $80 \mu \mathrm{L}$ of medium was added instead. $20 \mu \mathrm{L}$ of the corresponding well on the 'mixing plate' was then added to the cell suspension on the 'experimental plate' which was subsequently incubated in a humidified atmosphere containing $5 \% \mathrm{CO}_{2}$ at $37^{\circ} \mathrm{C}$. After $48 \mathrm{~h}, 10 \mu \mathrm{L}$ of alamarBlue ${ }^{\circledR}$ cell viability reagent was added to each well (except for three wells containing medium only). After 3-3.5 h of incubation under the same growth conditions, the absorbance at 570 and $600 \mathrm{~nm}$ of each well was measured by UV-vis spectrophotometer. The absorbances of each well were corrected against the medium-only wells without alamarBlue ${ }^{\circledR}$ reagent and the $R_{\mathrm{O}}$ correction factor for each plate was calculated as follows: $R_{\mathrm{O}}=$ Corrected $\lambda_{570}$ of alamarBlue ${ }^{\circledR}$ in media/Corrected $\lambda_{600}$ of alamarBlue ${ }^{\circledR}$ in media. Subsequently, the amount of reduced alamarBlue ${ }^{\circledR}\left(\mathrm{AR}_{570}\right)$ was calculated for each well as follows:

$$
\mathrm{AR}_{570}=\text { Corrected } \lambda_{570}-\left(\text { Corrected } \lambda_{600} \times R_{\mathrm{o}}\right)
$$

$\mathrm{AR}_{570}$ for each well was then expressed as a percentage of growth control. Note that all experiments were conducted in triplicate on three different occasions and error bars shown represent the standard error of the mean of independent experiments.

\section{Cellular uptake}

The hydrolysed, cross-linked vesicle, HXV (2 mg) were dissolved in $1 \mathrm{~mL}$ DI water, then $0.34 \mathrm{mg}$ EDCI $([\mathrm{COOH}]$ : [EDC] = 4) and $0.005 \mathrm{mg}$ AF594 were added to the solution. The mixture was then reacted at R.T. for $48 \mathrm{~h}$ after which any excess AF594 was removed by dialysis against deionized (DI) water.

On day-1 sterile round glass cover slips $(\varnothing 15 \mathrm{~mm})$ were placed in the wells of a 12 well plate and HeLa cells were seeded in 'complete DMEM' medium at a cell density of 200000 cells per well in $0.5 \mathrm{~mL}$ seeding volume before the plate was placed in a humidified incubator (95-100\% humidity, $5 \% \mathrm{CO}_{2}$ ) overnight. On day 0 , the seeding medium was removed from each well and cells were gently washed with $1 \mathrm{~mL}$ sterile PBS. Approx. $0.5 \mathrm{~mL}$ fresh 'complete DMEM' medium and then $100 \mu \mathrm{L}$ vesicle suspension was added to each well. The plate was returned to the incubator for 12-24 h. On day 1 , the medium was removed from each well and cells were gently washed with PBS. Samples were fixed using paraformaldehyde before being mounted onto microscopy slides using DAPI Fluoromount $\mathrm{G}^{\mathrm{TM}}$ (ProSciTech). Samples were imaged by confocal microscope.

\section{Results and discussion}

The linear-brush diblock copolymers were synthesized via ring-opening metathesis polymerization (ROMP) of two (macro)monomers, oxanorbornenyl anhydride (ONBAn) and $\omega$-oxanorbornenyl poly(ethylene glycol) (ONB-PEG, $M_{\mathrm{n}}=$ $2.0 \mathrm{kDa}$ ) according to established procedures. ${ }^{19}$ Copolymers were subsequently self-assembled in dry acetone to afford polymeric vesicles with pendant anhydrides (Scheme 1). Thereafter, the acid-cleavable cross-linker 2,2'-(propane-2,2-diyl bis(oxy))diethanamine (PDDE) was utilized to stabilize the vesicular structure through reaction with the anhydride units in the bilayer membrane. After hydrolysis of any unreacted anhydrides, the platinum drug was loaded into the cross-linked vesicles with high loading content. The cross-linked vesicles are designed to degrade gradually at $\mathrm{pH}=5.5$, accompanied by the release of cisplatin in saline solution.

\section{Synthesis of cross-linked polymer vesicles}

ROMP is a powerful and broadly applicable approach for the preparation of macromolecular materials. ${ }^{25,26}$ The linearbrush diblock copolymer poly $\left(\mathrm{ONBAn}_{35}-b\right.$-ONB-PEG $\left.{ }_{5}\right)$ was prepared via efficient ROMP as follows: ONBAn (35.0 equiv.) was exposed to pyridine modified Grubbs second-generation catalyst (cat., 1.0 equiv.) for $20 \mathrm{~min}$. ONB-PEG (5.0 equiv.) was then added, and the mixture was stirred for $1 \mathrm{~h}$ at room temperature. The formed linear-brush copolymer has a molecular weight of $14.9 \mathrm{kDa}$ with a narrow polydispersity of 1.21 (Fig. 1A). The high conversion of ONB-PEG macromonomers (MMs) in ROMP was revealed by ${ }^{1} \mathrm{H}$ NMR spectroscopy. In Fig. 1B, the olefin proton resonances a at $\delta 6.50 \mathrm{ppm}$ (refer to spectrum 1) totally disappeared after ROMP, which confirms the quantitative consumption of the MMs. The 'ene' proton resonance of the linear-brush backbone $\mathrm{a}^{\prime}$ (trans/cis) at $\delta$ 5.4-5.8 ppm (refer to spectrum 2) derived from ring-opening metathesis was observed, which further verified the formation of the linear-brush diblock copolymer.

The self-assembly of poly $\left(\mathrm{ONBAn}_{35}-b-\mathrm{ONB}^{\left.-\mathrm{PEG}_{5}\right)}\right.$ was then performed in dry solvents to protect the anhydride units. The assembled structure formed upon addition of acetone (which is a non-solvent for the poly(ONBAn) block of the diblock copolymer) to the common solvent THF. Firstly, the diblock copolymer was dissolved in dry THF. Subsequently, the slow addition of dry acetone led to the aggregation of the poly(ONBAn) block to form a micellar solution. Residual THF was then removed via dialysis against an excess of dry acetone. TEM analysis indicated the formation of micellar structure (see Fig. S1 in ESI $\dagger$ ) and dynamic light scattering (DLS) measurements revealed an intensity-average hydrodynamic diameter, $D_{\mathrm{h}}$, of $\sim 95 \mathrm{~nm}$ and a polydispersity of 0.03 (see Fig. S2 in ESI $\dagger$ ) for these assembles.

The self-assembled structure was then stabilized through partial cross-linking of the ONBAn units (i.e. 28 mol\%) using an equivalent amount of the acid-degradable cross-linker PDDE. Utilization of this cross-linker means, that the resulting cross-linked polymer vesicles are biodegradable in an endosomal/lysosomal environment $(\mathrm{pH} \sim 5)$. Given once degraded 


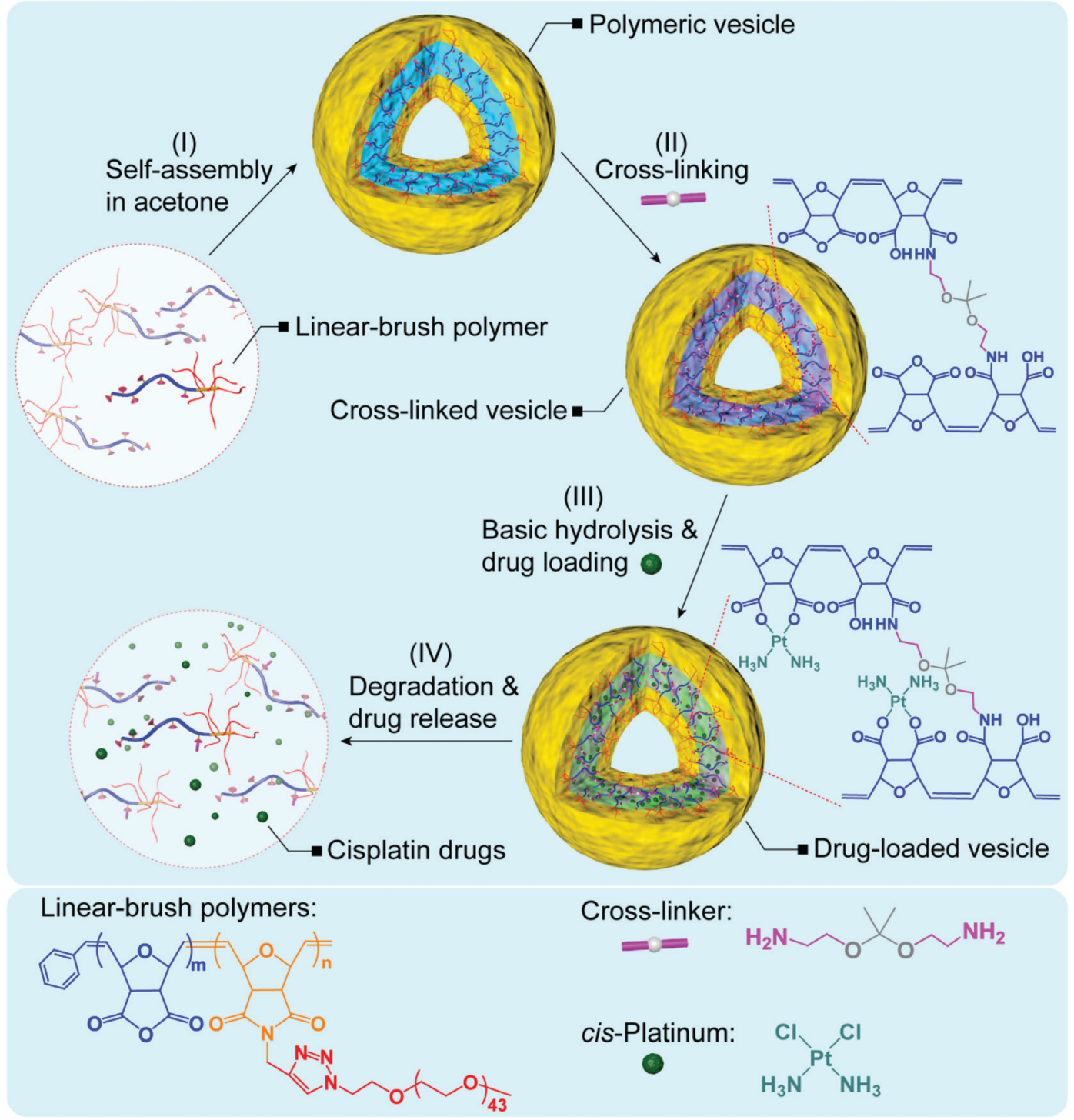

Scheme 1 The synthetic route towards nontoxic, acid-degradable polymer vesicles for the delivery of platinum drugs.

into the linear-brush diblock copolymers no further degradation into molecular components is possible, the degradation products can nonetheless be cleared from the body since their molecular weights are below the renal clearance threshold (40 kDa for linear PEG). ${ }^{27}$ The DLS measurement of the crosslinked nanoparticles revealed a $D_{\mathrm{h}}$ of $\sim 96 \mathrm{~nm}$ (see Fig. S2 in ESI†). In addition, nanoparticles with different degrees of cross-linking (DOC, i.e., $14 \mathrm{~mol} \%$ and $56 \mathrm{~mol} \%$ ) were prepared in parallel according to similar procedures.

Thereafter, hydrolysis of the anhydride functionalities was carried out in $0.1 \mathrm{M} \mathrm{NaOH}$ solution for 30 minutes. The ONBAn units were converted to ONB-diacid functionalities according to our previous study. ${ }^{19}$ After dialysis against deionized (DI) water, the micellar solutions were freeze-dried to give hydrolysed, cross-linked vesicles. Cryo-TEM images without staining showed uniform nanoparticles with an increased $D_{\mathrm{h}}$ of $\sim 240 \mathrm{~nm}$ (Fig. $2 \mathrm{~A}$, DOC of $28 \mathrm{~mol} \%$ ) due to increased solubility resulting in swelling of nanoparticles, which agreed with the results from DLS measurements (see Fig. S3 in ESI†). Additionally, the definable bilayer membrane with $\sim 50 \mathrm{~nm}$ thickness was observed from cryo-TEM images (Fig. 2B), clearly indicating a vesicular morphology. Additionally, TEM observation also indicated some asymmetric and imperfect vesicles.

Fig. 3A reveals the effect of DOC on vesicle size. At low DOC ( $14 \mathrm{~mol} \%$ ), the hydrolysed particles presented a $D_{\mathrm{h}}$ of $330 \mathrm{~nm}$. In contrast, high DOCs of $28 \mathrm{~mol} \%$ and $56 \mathrm{~mol} \%$ resulted in a significantly reduced $D_{\mathrm{h}}$ of $240 \mathrm{~nm}$. DLS studies also confirmed the $\mathrm{pH}$ responsiveness of the cross-linked nanoparticles with DOC of $28 \mathrm{~mol} \%$. Fig. 3B shows that the particle size did not change as the $\mathrm{pH}$ decreased from 13 to 5 with $D_{\mathrm{h}}$ of $\sim 240 \mathrm{~nm}$, indicating stable structure of the crosslinked vesicles under a range of $\mathrm{pH}$ value after cross-linking. However, the particle size abruptly decreased from $240 \mathrm{~nm}$ to 

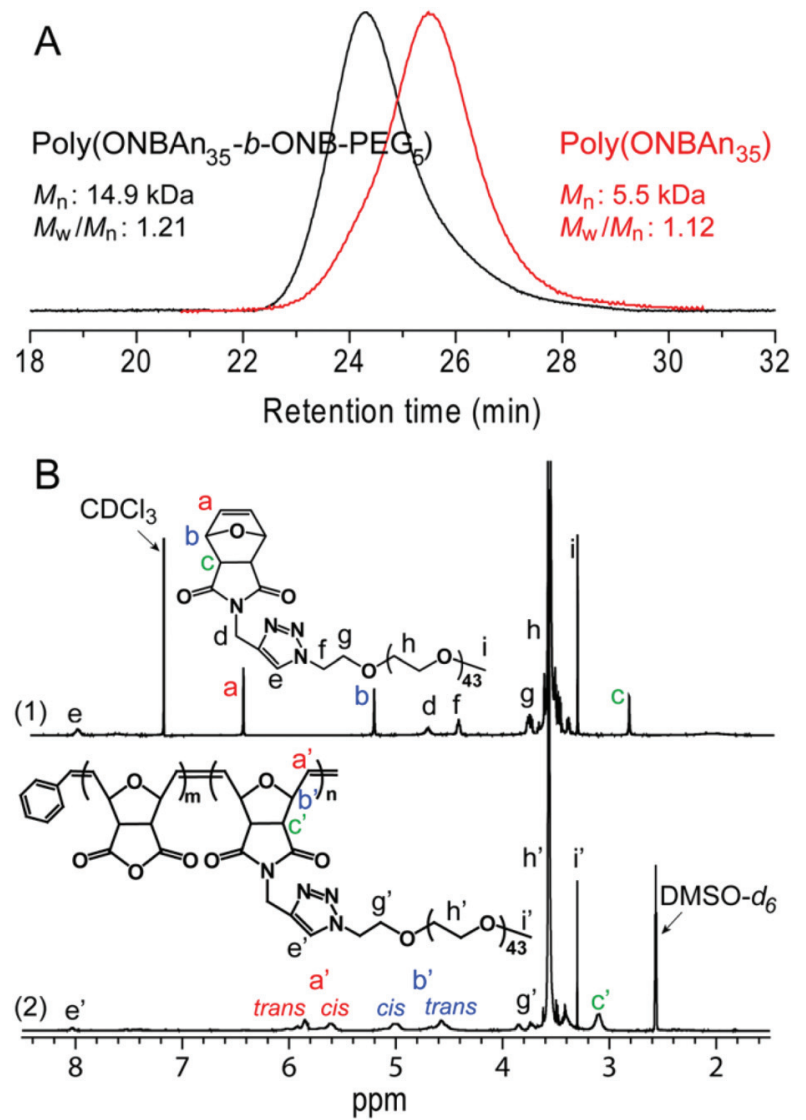

Fig. 1 Characterization of linear-brush diblock copolymers poly(ONBAn $_{35}-b-\mathrm{ONB}-\mathrm{PEG}_{5}$ ) (A) GPC measurements and (B) ${ }^{1} \mathrm{H} N M R$ spectroscopic analysis.

$170 \mathrm{~nm}$ as $\mathrm{pH}$ decreased from 5 to 3 . This observation cannot be attributed to the disassembly of cross-linked vesicles but is suggestively attributed to inter-polymer complex (IPC) formation between poly(ONB-diacid) block and poly(ONB-PEG)
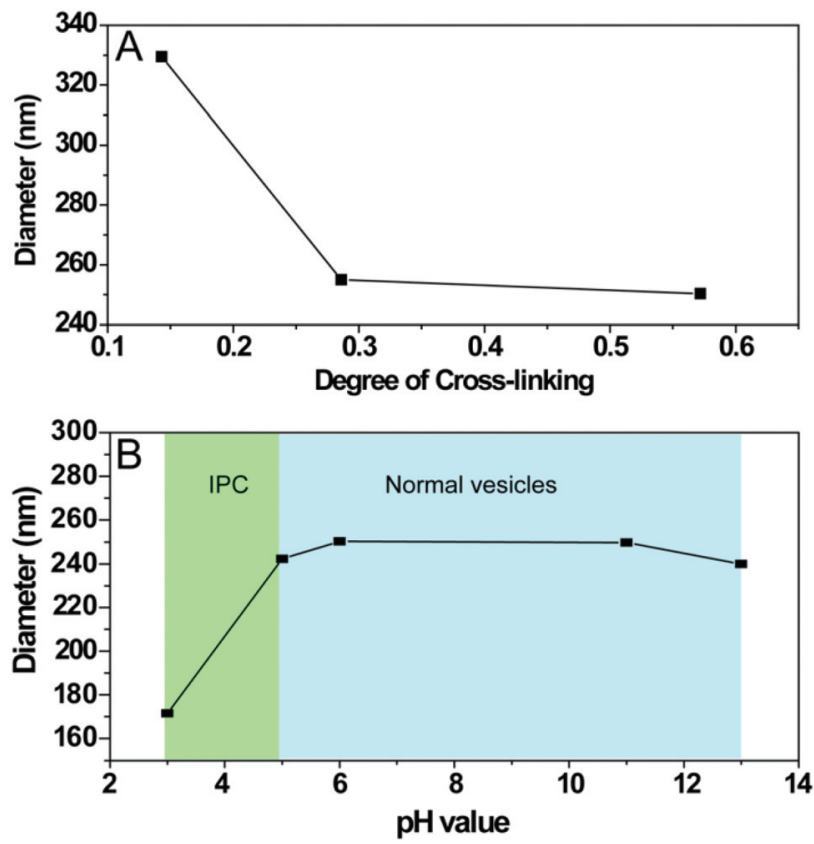

Fig. 3 Hydrodynamic diameter of cross-linked polymeric vesicles as measured by DLS as a function of (A) degree of cross-linking (DOC) and (B) $\mathrm{pH}$ values.

brush, as discovered by us previously. ${ }^{28,29}$ It should be emphasized that due to the short exposure $(<3 \mathrm{~min})$ of cross-linked vesicles to acidic media $(\mathrm{pH}<5)$, no degradation of crosslinked vesicles was observed during DLS measurements.

\section{Drug loading and release}

The bidentate functionality (di-acid) is an ideal conjugation site for cisplatin due to its strong tendency to bind cisplatin through the formation of dicarboxylate-platinum complexes. ${ }^{19,30}$ These metal complexes with a 6-8 member ring structure provide increased stability and high loading contents
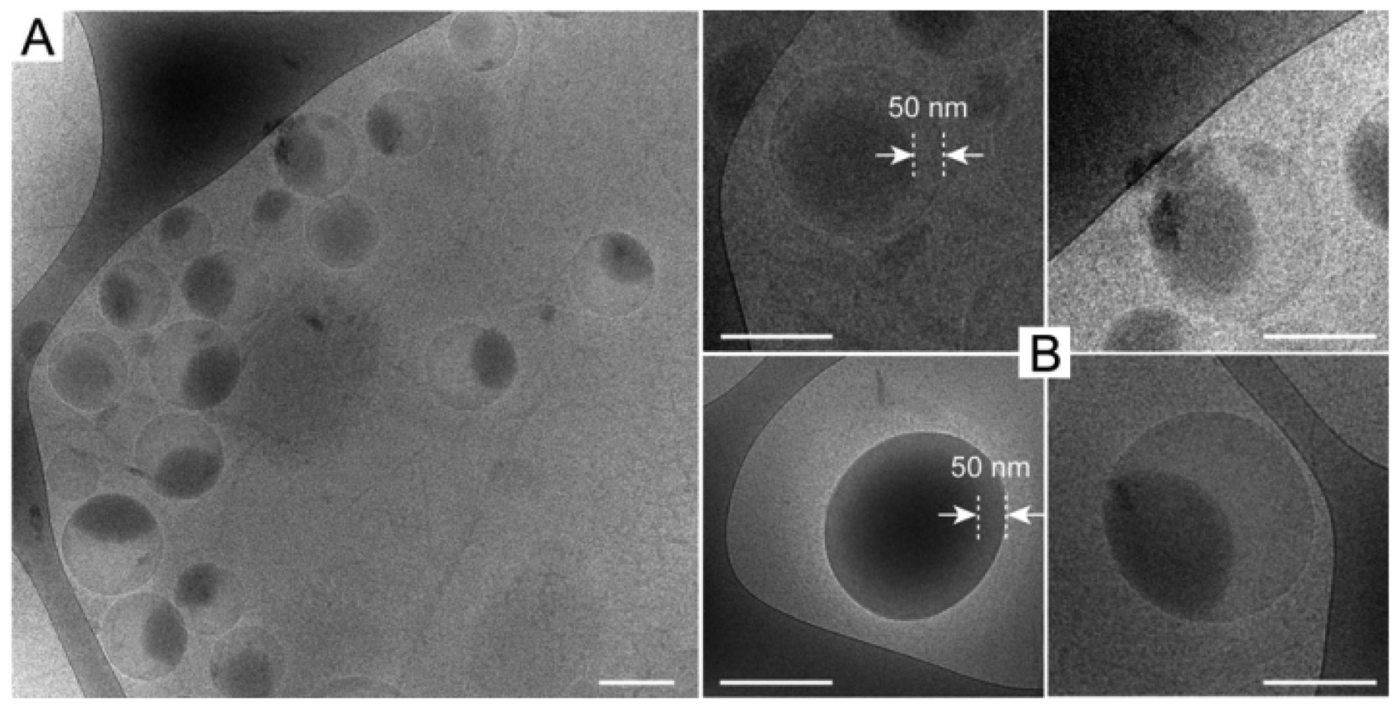

Fig. 2 Cryo-TEM images of cross-linked polymeric vesicles without staining. The scale bar represents $200 \mathrm{~nm}$. 
to the conjugates. ${ }^{30}$ In the present study, the hydrolysed poly(ONB-diacid) segments of the cross-linked vesicles with DOC of $28 \mathrm{~mol} \%$ were conjugated to cisplatin according to a previously reported procedure. ${ }^{13}$ The formed drug-loaded vesicles exhibited a high drug conjugation efficiency of $85.2 \%$ as determined by TGA (Fig. 4A). This result indicates that the anhydride groups were converted to bidentate diacid functionalities and most of them have been involved in the complex formation. The drug loading content was calculated to be $17.6 \mathrm{wt} \%$ (see ESI $\dagger$ ), which is much higher than other complex counterparts in matrix systems reported in the literature $(\sim 10 \mathrm{wt} \%) .{ }^{4,31}$

The in vitro release of the CDDP was performed using a well-established method..$^{20,30}$ The release of cisplatin, CDDP, from the drug-loaded vesicles can be initiated in the presence of saline solution, which can lead to ligand exchange of the platinum complex thus converting it from a carboxylato to a chloride complex. ${ }^{32}$ In order to investigate the cooperative effect of degradation of the drug carrier in acidic condition
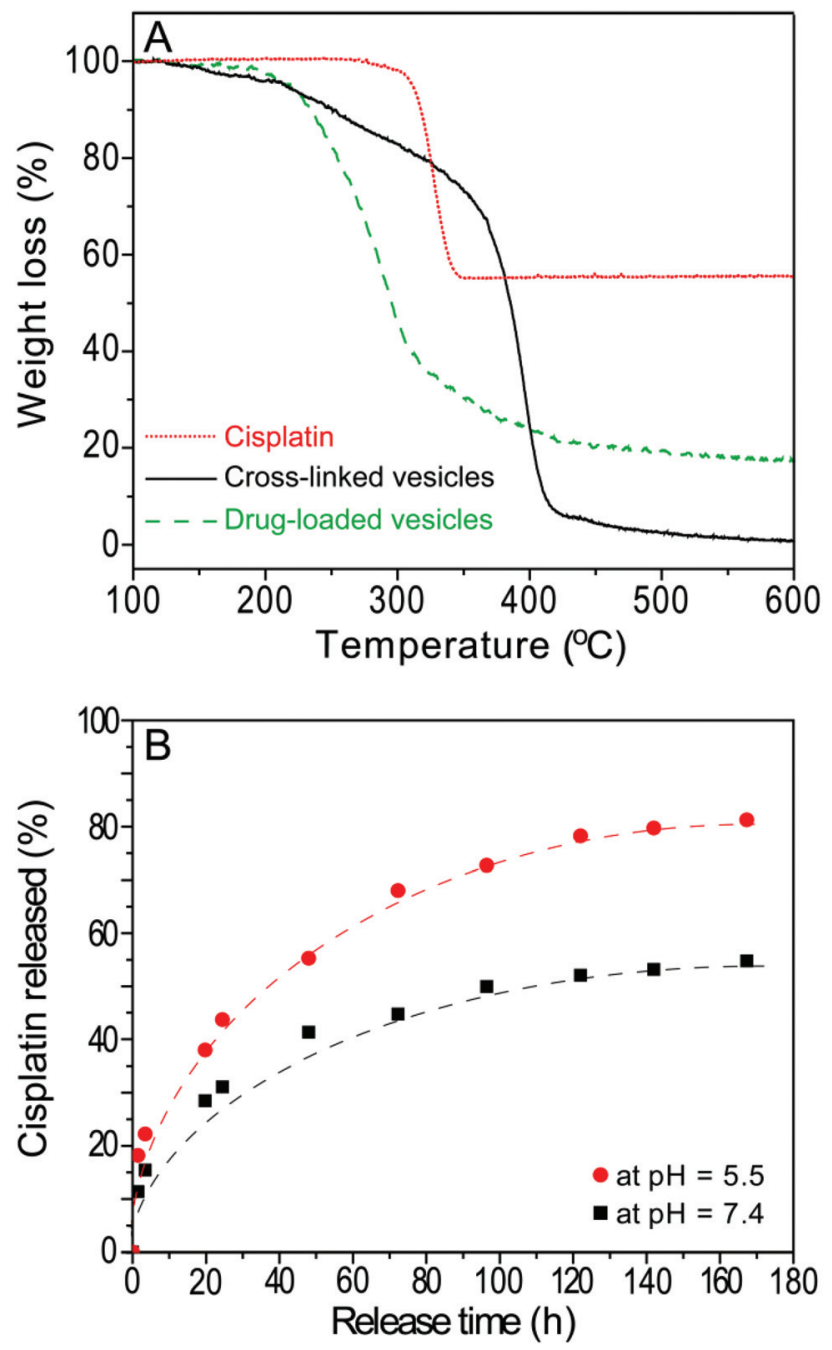

Fig. 4 (A) TGA traces for cisplatin, cross-linked vesicles and drugloaded vesicles. (B) Release profile of cisplatin from drug-loaded vesicles in saline solution $(0.9 \mathrm{wt} . \% \mathrm{NaCl})$ at $\mathrm{pH} 5.5(\bullet)$ and $\mathrm{pH} 7.4$ (口). The line was fitted according to equation: \% CDDP released $=A \exp (-t / \tau)+y_{0}$. and the chloride-mediated release of CDDP from the drugloaded vesicles, drug release was performed in $0.9 \mathrm{wt} \% \mathrm{NaCl}$ at pH 5.5 as well as pH 7.4 for comparison (Fig. 4B). Over one week, the release profile reaches a plateau at $\sim 50 \%$ at $\mathrm{pH} 7.4$, while up to $80 \%$ of the drugs are released at $\mathrm{pH} 5.5$ over the same time period. The value presented in this study is higher than that of cross-linked micelles (up to $70 \%$ higher) ${ }^{12,30}$ and non-crosslinked micelles (PLGA- $b$-mPEG, ranging from 30 to $70 \%$ higher $)^{32}$ The release rates can be described by a simple model assuming first-order kinetics ${ }^{12}$ with different release constants $(\tau)$ of $47.8 \mathrm{~h}$ and $39.1 \mathrm{~h}$ at $\mathrm{pH} 5.5$ and $\mathrm{pH} 7.4$, respectively. This observation indicates that more drugs will be released under an endosomal environment within the cell, compared to the physiological $\mathrm{pH}$ observed during circulation in the body. This result also demonstrates that the degradation of vesicles increases the drug release rate, thus, the actual release process in vivo may combine diffusion of the drug (out of the polymeric vesicles), chemically controlled de-complexation of the drug-polymer complex and degradation of the polymer vesicles.

\section{Cell culture}

The cytotoxicity of parental linear-brush diblock copolymer poly(ONB-diacid ${ }_{35}-b$-ONB-PEG 5 ), unconjugated cross-linked vesicle, degraded cross-linked vesicle, drug-loaded cross-linked vesicle, degraded drug-loaded crosslinked vesicle and free drug was evaluated over a $48 \mathrm{~h}$ time period using a simple endpoint viability assay (Fig. 5). Cervical cancer cells (HeLa) were exposed to varied concentrations of investigated polymer materials and free drug ranging from $10^{-6}$ to $10^{-2}$ mol $\mathrm{Pt} \mathrm{L}^{-1}$. The $\mathrm{IC}_{50}$ values were determined using the logarithmic concentration.

As shown in Fig. 5, no observed toxicity of the parental linear-brush diblock copolymer, unconjugated cross-linked vesicle and degraded cross-linked vesicle was detected after $48 \mathrm{~h}$ exposures to cancer cells. As expected, the free drug and the degraded drug-loaded vesicle showed comparable cytotoxicity, with $\mathrm{IC}_{50}$ values of $85 \pm 4.2 \mu \mathrm{mol} \mathrm{Pt} \mathrm{L}^{-1}$ and $81 \pm$ $6 \mu \mathrm{mol} \mathrm{Pt} \mathrm{L} \mathrm{L}^{-1}$, respectively. It is worth to note that the drugloaded vesicle showed a lower $\mathrm{IC}_{50}$ value of $50 \pm 6.0 \mu \mathrm{mol} \mathrm{Pt}$ $\mathrm{L}^{-1}$ (thus higher cytotoxicity), even though in total only $50 \%$ of the drug would have been released from the drug carrier during the $48 \mathrm{~h}$ the assay was conducted (see Fig. $4 \mathrm{~B}, \mathrm{pH}=$ 5.5 curve). Considering $80 \%$ cisplatin release from the drugloaded vesicles is to be expected upon one week, the $\mathrm{IC}_{50}$ is in reality even lower than that. This result suggests that the polymer vesicles are a highly efficient means of delivering cisplatin to cancer cells. Internalization of drug-loaded vesicles/ carriers (rather than diffusion of the free drug) is often more efficient since the uptake mechanism differs from that of the corresponding free drug. Free drugs are required to diffuse through the cell membrane, which often is an inefficient process due to multidrug resistance (MDR) efflux pumps. ${ }^{33}$ Endocytotic uptake of drug-loaded vesicles, which can overcome MDR mechanisms, is thought to cause greater drug efficiency due to the avoidance of MDR efflux pumps. 


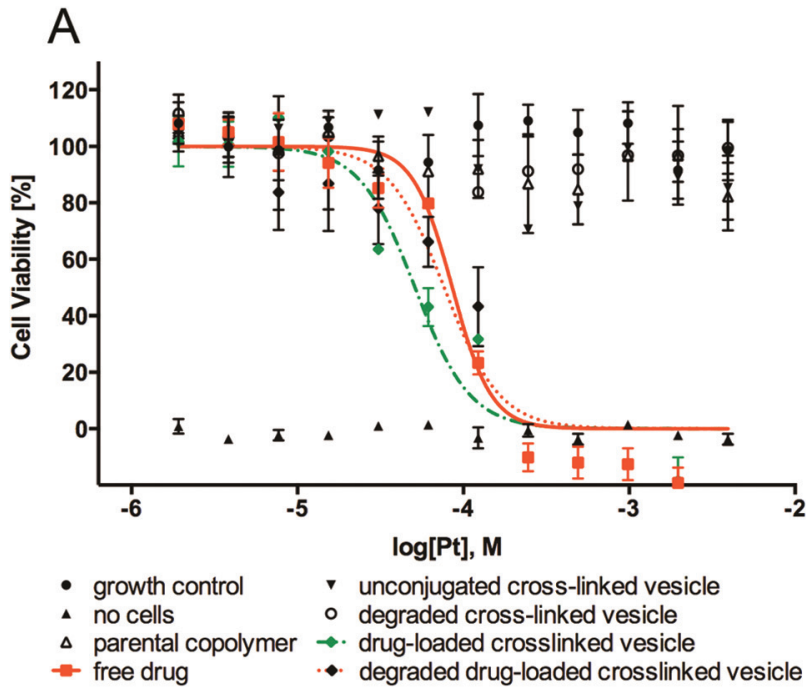

B

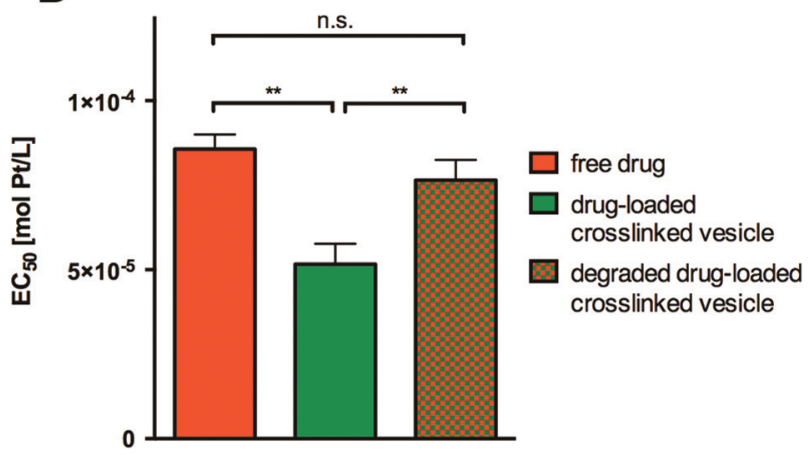

Fig. 5 (A) Cell viability of HeLa cells after $48 \mathrm{~h}$ of exposure to parental linear-brush diblock copolymer (poly(ONB-diacid) 35 -b-poly(ONB-PEG) $)_{5}$ ), unconjugated cross-linked vesicle, degraded cross-linked vesicle, drugloaded cross-linked vesicle, degraded drug-loaded cross-linked vesicle and free drug. (B) $E_{50}$ values for free drug, drug-loaded cross-linked vesicle and degraded drug-loaded cross-linked vesicle ${ }^{* *} p<0.001, n=$ 27-33).

In order to confirm that the developed drug-loaded vesicles are indeed internalized by cells and may thus deliver their payload intracellularly, we conducted cellular uptake studies with unconjugated (non-drug loaded), cross-linked vesicles using the same cell type. For this purpose, a fluorescent tag, Alexa Fluor®594 (AF594), was introduced into the cross-linked vesicles via reaction with the di-acid functionalities in the bilayer membrane, and HeLa cells were exposed to such AF594-tagged vesicles for $24 \mathrm{~h}$. As shown in Fig. 6, the red fluorescence associated with the vesicles is clearly observed within the cells' cytoplasm rather than being located outside or colocated with the cell wall after this time period, which indicates successful cellular uptake. The observed fluorescence is further well distributed within the cytoplasm rather than being observed inside discrete intracellular vesicles (endosomes/lysosomes). Lastly, treated cells appear with normal morphology (i.e., no cell shrinking, membrane blebbing, chromatin condensation, nucleus fragmentation, apoptotic bodies or membrane permeability are observed), confirming the benign nature of the empty, cross-linked vesicles already discussed in Fig. 5.

\section{Conclusions}

In summary, this work presented an improved approach to fabricate acid-degradable, polymeric vesicles for the efficient delivery of cisplatin drug. The vesicles were synthesized via the self-assembly of linear-brush diblock copolymers and subsequent cross-linking using an acid-degradable cross-linker. The utilization of hydrolysed anhydrides allowed for the straightforward, efficient and stable conjugation of cisplatin to the cross-linked polymer vesicles. Moreover, the cross-linked drug carriers are designed to degrade at lysosomal acid condition ( $\mathrm{pH} \sim 5.5$ ), which leads to augmented drug release compared to $\mathrm{pH}$ 7.4. The activity of the cisplatin loaded into the cross-linked vesicle was improved in comparison to the free drug (and the degraded drug-loaded vesicle control) and this is potentially due to the different uptake mechanism of the drug. These initial biological evaluations demonstrated the feasibility of this novel drug delivery system and further studies along with an in vivo analysis of the current system are ongoing.
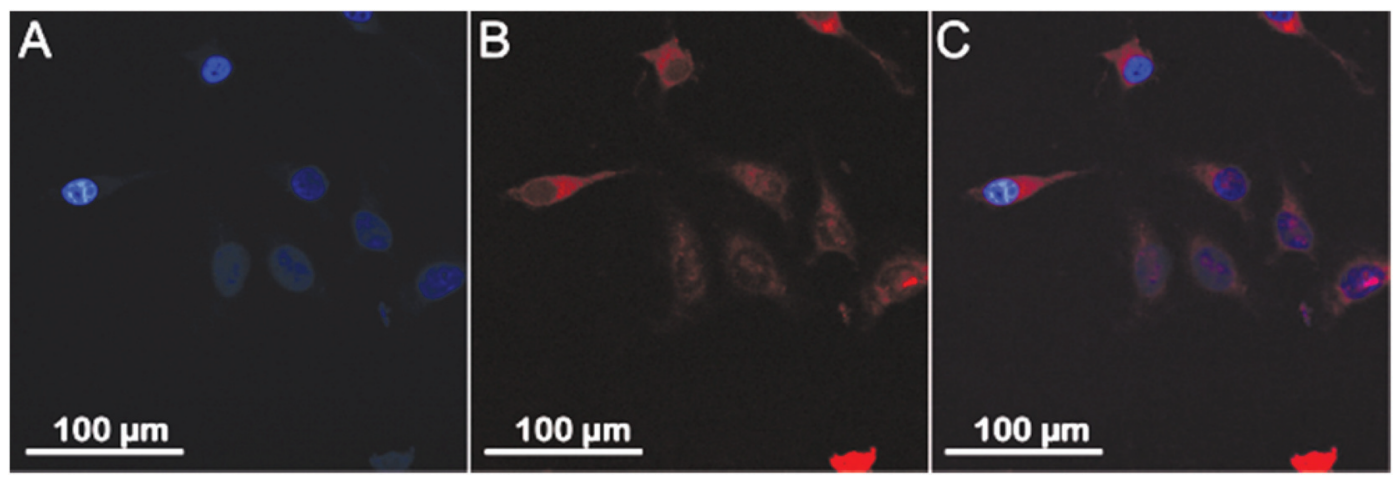

Fig. 6 Confocal laser scanning microscopy (CLSM) images of HeLa cells $24 \mathrm{~h}$ after the addition of AF594-tagged vesicles. (A) Cell nuclei were stained using 4',6-diamidino-2-phenylindole (DAPI) staining. (B) AF594-tagged vesicles are internalized within cells. (C) Composite image. 


\section{Acknowledgements}

The authors acknowledge the Australian Research Council under the Future Fellowship Scheme (FT110100411, G.G.Q.). Q.F. and K.L. are the recipients of an Australian Research Council Super Science Fellowship (FS110200025). Q.F. also wishes to acknowledge the receipt of 2013 Early Career Researcher Grants from The University of Melbourne.

\section{Notes and references}

1 L. Kelland, Nat. Rev. Cancer, 2007, 7, 573-584.

2 D. Wang and S. J. Lippard, Nat. Rev. Drug Discovery, 2005, 4, 307-320.

3 J. Reedijk, Eur. J. Inorg. Chem., 2009, 10, 1303-1312.

4 E. Gianasi, M. Wasil, E. G. Evagorou, A. Keddle, G. Wilson and R. Duncan, Eur. J. Cancer, 1999, 35, 994-1002.

5 E. Soussan, S. Cassel, M. Blanzat and I. Rico-Lattes, Angew. Chem., Int. Ed., 2009, 48, 274-288.

6 K. S. Soppimath, T. M. Aminabhavi, A. R. Kulkarni and W. E. Rudzinski, J. Controlled Release, 2001, 70, 1-20.

7 M. H. Stenzel, Chem. Commun., 2008, 3486-3503.

8 J. Panyam and V. Labhasetwar, Adv. Drug Delivery Rev., 2003, 55, 329-347.

9 H. Wang, L. Tang, C. Tu, Z. Song, Q. Yin, L. Yin, Z. Zhang and J. Cheng, Biomacromolecules, 2013, 14, 3706-3712.

10 Y. Matsumura and H. Maeda, Cancer Res., 1986, 46, 63876392.

11 H. Maeda, J. Wu, T. Sawa, Y. Matsumura and K. Hori, J. Controlled Release, 2000, 65, 271-284.

12 V. T. Huynh, P. d. Souza and M. H. Stenzel, Macromolecules, 2011, 44, 7888-7900.

13 V. T. Huynh, G. Chen, P. d. Souza and a. M. H. Stenzel, Biomacromolecules, 2011, 12, 1738-1751.

14 L. Liao, J. Liu, E. C. Dreaden, S. W. Morton, K. E. Shopsowitz, P. T. Hammond and J. A. Johnson, J. Am. Chem. Soc., 2014, 136, 5896-5899.
15 B. M. Discher, Y.-Y. Won, D. S. Ege, J. C.-M. Lee, F. S. Bates, D. E. Discher and D. A. Hammer, Science, 1999, 284, 11431146.

16 D. E. Discher and A. Eisenberg, Science, 2002, 297, 967973.

17 R. Cheng, F. Meng, C. Deng, H.-A. Klok and Z. Zhong, Biomaterials, 2013, 34, 3647-3657.

18 C. J. F. Rijcken, O. Soga, W. E. Hennink and C. F. vanNostrum, J. Controlled Release, 2007, 120, 131-148.

19 J. Xu, Q. Fu, J. M. Ren, G. Bryant and G. G. Qiao, Chem. Commun., 2013, 49, 33-35.

20 V. T. Huynh, S. Binauld, P. L. d. Souza and M. H. Stenzel, Chem. Mater., 2012, 24, 3197-3211.

21 R. B. Woodward and H. Baer, J. Am. Chem. Soc., 1948, 70, 1161-1166.

22 D. Le, V. Montembault, J.-C. Soutif, M. Rutnakornpituk and L. Fontaine, Macromolecules, 2010, 43, 5611-5617.

23 J. A. Love, J. P. Morgan, T. M. Trnka and R. H. Grubbs, Angew. Chem., Int. Ed., 2002, 41, 4035-4037.

24 B. Schechter, A. Neumann, M. Wilchek and R. Arnon, J. Controlled Release, 1989, 10, 75-87.

25 C. W. Bielawskia and R. H. Grubbs, Prog. Polym. Sci., 2007, 32, 1-29.

26 Q. Fu, J. M. Ren and G. G. Qiao, Polym. Chem., 2012, 3, 343-351.

27 F. M. Veronese and G. Pasut, Drug Discovery Today, 2005, 10, 1451-1458.

28 B. S. Lele and A. S. Hoffman, J. Controlled Release, 2000, 69, 237-248.

29 P. Ivopoulos, M. Sotiropoulou, G. Bokias and G. Staikos, Langmuir, 2006, 22, 9181-9186.

30 V. T. Huynh, J. Y. Quek, P. L. d. Souza and a. M. H. Stenzel, Biomacromolecules, 2012, 13, 1010-1023.

31 R. Tong and J. Cheng, Angew. Chem., Int. Ed., 2008, 47, 4830-4834.

32 K. Avgoustakis, A. Beletsi, Z. Panagi, P. Klepetsanis, A. G. Karydas and D. S. Ithakissios, J. Controlled Release, 2002, 79, 123-135.

33 C. Vauthier, C. Dubernet, C. Chauvierre, I. Brigger and P. Couvreur, J. Controlled Release, 2003, 93, 151-160. 